\title{
ADHD and Sleep Problems in Children
}

\author{
Elizabeth Hastings and Barbara T. Felt \\ Section of Developmental Behavioral Pediatrics, Division of Child Behavioral Health, \\ Department of Pediatrics and Communicable Diseases, \\ University of Michigan, \\ USA
}

\section{Introduction}

In the evaluation of Attention Deficit Hyperactivity Disorder (ADHD), medical and behavioral problems related to sleep are important to consider. A relationship between ADHD and sleep has been acknowledged for some time. Sleep disturbances were among criteria for ADHD diagnosis in the past and rating scales for ADHD included items related to sleep disturbance (American Psychiatric Association [APA], 1987; Conners, et al. 1998, 1998). While our knowledge about the relationship between ADHD and sleep problems has improved in recent years, it remains challenging to tease apart the effect of insufficient or poor quality sleep on attention, alertness, learning and behavior and what might be due to a primary ADHD, mood or behavior problem (Simonds, 1984). This interface of mental health disorder and sleep disorder is a challenge many clinicians face in practice. Medical, mental health, behavioral and psychosocial factors can directly affect the quality and duration of sleep. Poor sleep, in turn, can have effects on daytime functioning and health. In addition, such medical and mental health problems can have direct effects on attention, learning and behavior. Sorting out the important contributing factors during a comprehensive evaluation can be challenging due to sleep and ADHD problems commonly co-occurring. The primary purpose of this chapter is to highlight the importance of including the evaluation of sleep as a part of the assessment of disorders such as ADHD because the best management for the individual patient depends on the accuracy of the diagnostic evaluation.

As discussed in other chapters in this book, ADHD is a common disorder that presents in childhood. It is estimated to affect $5-10 \%$ of school-age children and adolescents (Committee on Quality Improvement, 2000). Symptoms such as distractibility, forgetfulness and failure to complete work typify inattentive-type ADHD. Impulsivity, over activity and being fidgety are among symptoms that are common for individuals with hyperactive-impulsive type ADHD. Having symptoms that meet criteria for both subtypes is required for a diagnosis of combined-type ADHD. DSM-IV criteria require that symptoms have onset before age 7 years (APA, 2000); however, the symptoms of inattentive-type ADHD are often subtle and not recognized until later school years when the academic curriculum is more challenging and requires greater executive functioning skills to keep pace and do well. In addition, the symptoms of ADHD are non-specific on their own and can be related to other factors, contexts and diagnoses. Due to this, it can be challenging to determine if the pattern of an individual's behavior is best described by the diagnosis of ADHD. 
Sleep problems occur commonly, from infancy through childhood and adolescence and are related to daytime behavioral concerns. For instance, bedtime resistance and night waking are common among toddlers and preschoolers, affecting $30 \%$ or more. A significant relationship between sleep problems and parent-reported concerns about internalizing and externalizing behaviors has been demonstrated for this age group (Reid, 2009; Mindell, 2010). Among school-age children, 11 to $37 \%$ have problems with sleep and many describe feeling sleepy during the day (Sleep in America Poll Summary of Findings [SAP], 2004). Studies of adolescents and the 2006 National Sleep Foundation Poll of US adolescents nationwide also describe a high prevalence of sleep problems at this age (Owens, 2005; SAP, 2006). Forty-five percent of adolescents report short night time sleep durations and more than half report feeling tired or sleepy during the day. Many adolescents also report feeling unhappy and that they are not getting enough sleep.

In this chapter, we will discuss: the neurobiological aspects of ADHD and sleep; typical patterns of normal sleep for children and expected age-related changes; common sleep disorders and their effects on daytime functioning with particular attention to ADHD; sleep characteristics for children with ADHD and the effects of medications; and the importance of screening for sleep concerns in the evaluation and management of ADHD.

\section{Neurobiology}

\subsection{Neurobiology of ADHD}

To review our current understanding about the overlap of ADHD and sleep from a neurobiological perspective, we will briefly review key concepts for ADHD, and sleep in this section. Although the pathophysiology of ADHD is quite complex and likely results from a combination of multiple factors, genetic and environmental variables have been identified as possible contributing components (Faraone, 1998). Anatomical studies have isolated abnormalities in brain regions associated with cognition, executive functioning and behaviors consistent with ADHD (Dahl, 1996). Functional MRI (fMRI) studies have similarly demonstrated abnormal activation in these areas, including the prefrontal cortex, anterior cingulate gyrus and thalamus (Durston, 2003; Rubia et al., 2011). Gross anatomic studies have demonstrated a lower total brain volume in children with ADHD (Curatolo et al., 2009; Makris et al., 2009; Tripp, 2009). Additionally, decreased size of the right frontal lobe (RFL), corpus callosum, striatum and cerebellum have been observed in children and adolescents with ADHD (Curatolo et al., 2009; Makris et al., 2009; Tripp, 2009). The areas found to be different in ADHD are those which support emotion and higher brain functions including executive function and attention (Makris et al., 2009). Abnormalities observed in the cerebrum and cerebellum have been found to persist with advancing age, whereas, abnormalities in the caudate normalize with age (Curatolo et al., 2009; Konrad \& Eickhoff, 2010).

These anatomical studies and elucidating the mechanisms of stimulant medications used to treat ADHD, have helped to further our understanding of the neurobiological basis of this condition. ADHD is associated with catecholamine dysregulation, specifically related to dopamine and norepinephrine (Curatolo et al., 2009; Faraone, 1998, 2005; Gonon, 2009; Makris et al., 2009; Rosa-Neto et al., 2005; Swanson, 2000; Tripp, 2009). The dysregulation of dopamine in ADHD has been the focus of much inquiry. One neurophysiologic finding 
characteristic of ADHD, which is thought to underlie some ADHD symptoms, is an atypical response to reward (Tripp, 2009; Nigg, 2005). Dopamine is thought to be an important component of the neural system of reward (Tripp, 2009), as well as for ADHD. The brain regions believed to be important in children and adults with ADHD, in which gross anatomic differences have been demonstrated, are rich in dopamine signaling (Curatolo et al., 2009; Makris et al., 2009; Tripp, 2009). Additionally, genes associated with ADHD are involved in the regulation of extracellular dopamine (Faraone, 1998, 2005; Swanson, 2000). The therapeutic mechanism of stimulant treatment is related to dopamine and other catecholamines, and stimulant treatment is most often used in ADHD (Del Campo et al., 2011; Rosa-Neto et al., 2005; Rubia et al., 2011). Methylphenidate exerts a therapeutic effect for ADHD by increasing the extracellular availability of dopamine (and norepinephrine) by blocking the reuptake of dopamine via transporter binding (Del Campo et al., 2011; Tripp, 2009; Faraone, 1998). Amphetamines work similarly to methylphenidate, but also increase the release of dopamine and norepinephrine and decrease the catabolic activity of monoamine oxidase (Del Campo et al., 2011). PET imaging studies have shown acute increases in extracellular dopamine with methylphenidate administration (Rosa-Neto et al., 2005). Thus, the stimulant medications are thought to correct an underlying deficit related to dopamine regulation and availability.

Additional catecholamines, including norepinephrine and serotonin are thought to play a role in ADHD; however the roles of these neurotransmitters are less well understood (Zimmer, 2009; Del Campo et al., 2011). Norepinephrine neurons are mainly located in the locus cerulus, part of the reticular activating system, which is thought to be an important center in regulating attention and arousal (Owens, 2005). As discussed above, extracellular norepinephrine levels are increased with the use of psychostimulant medications (Del Campo et al., 2011). Non-stimulant medications, atomoxetine and alpha-agonists, effectively increase extracellular norepinephrine levels and have also been successfully used in the treatment of ADHD. A serotonin transporter has been associated with ADHD (Faraone, 2005), although serotonin's role in ADHD has not yet been clarified.

\subsection{Neurobiology of sleep}

The neurobiology of sleep has also been a focus of study in recent years, and has become much better understood. As reviewed below, sleep has two distinct stages, non-rapid eye movement (non-REM) and rapid-eye movement (REM) that alternate in cycles through the night. non-REM sleep is a period of relatively low brain activity, although the brain's regulatory capacity is still active, and body movements are preserved. non-REM sleep can be further divided into stages 1-3 by the 'deepness' of the sleep, stage 3 being the deepest. REM sleep is a period of desynchronized cortical activity, high metabolic rate, lack of muscle tone and episodic bursts of rapid eye movements (Mindell, 2010). Arousal opposes sleep in the sleep-wake cycle, and the daily shift between these states requires a fine-tuned system of neural interactions (Dahl, 1996). Multiple, different neural systems have been implicated in the control of the waking state (Lu, 2010; Espana, 2004).

A 2-process model has been proposed to explain the interactions of different biologic mechanisms of sleep. The homeostatic process, which regulates length and depth of sleep, interacts with the endogenous circadian rhythm system, which influences the internal sleep organization and the timing and duration of daily sleep-wake cycles (Owens, 2005; Pace- 
Schott \& Hobson, 2002). The homeostatic process or sleep drive is dependent upon the quality and quantity of previous sleep, as well as the period of time spent awake; the sleep drive increases with longer waking periods, and poorer sleep quality or duration (Owens, 2005). The circadian rhythm is synchronized with a 24 hour day, with predictable periods of increasing arousal and sleepiness, which are linked to ambient light exposure (Owens, 2005). The light-dark cycle is a powerful zeitgeber or cue that entrains the circadian clock to the 24-hour day. The suprachiasmatic nucleus of the hypothalamus responds to these cues by influencing the production of melatonin. Under typical circumstances, as one nears the usual dark period, melatonin production increases and facilitates sleep onset. In addition to environmental cues which help to keep the circadian clock on track, genetics is also thought to play a role. Individuals appear to have a genetic propensity to be a "lark" (sleep-wake cycle set earlier) or a "night owl" (sleep-wake cycle set later).

The ascending arousal system consists of multiple neurotransmitters and produces cortical arousal through two pathways. The dorsal route ascends through the thalamus, and the ventral route through the hypothalamus and basal forebrain (Fuller, et. al, 2006). The arousal system is opposed by the ventrolateral preoptic nucleus (VLPO), which is active during sleep (Fuller, et. al, 2006). The VLPO initiates sleep after input from the circadian rhythm, and homeostatic process (sleep drive) (Pace-Schott \& Hobson 2002).

Many neurotransmitters have been implicated in the regulation of behavioral state in the sleep-wake cycle. During wakefulness and rapid eye movement (REM) sleep, cholinergic neurons in thalamus, hypothalamus \& dorsal midbrain activate the thalamocortical signaling to produce fast cortical rhythms (Espana, 2004; Lu, 2010). In non-REM sleep, however, these neurons are relatively inactive (Espana, 2004; $\mathrm{Lu}_{\prime}, 2010$ ). Neurons in the locus ceruleus (mainly producing norepinephrine) are active during waking, less active during non-REM sleep and demonstrate almost no activity during REM sleep (Espana, 2004). Norepinephrine induces cortical activation \& wakefulness, especially in the setting of stress (Espana, 2004; Lu, 2010). Similarly, neuronal histamine is found in the tuberomammillary nucleus, which is active during wakefulness, with less activity during non-REM sleep and even less during REM sleep (Espana, 2004). Histamine promotes wakefulness, especially at the time of waking and during conditions that require high behavioral arousal (Espana, 2004). Serotonin has also been connected to the regulation of behavioral state. The dorsal raphe nucleus is an important source of serotonin, and has (similarly to other aminergic neurons) been found to be most active during wakefulness, less so during non-REM sleep and virtually inactive during REM sleep (Espana, 2004). Orexin/hypocretin neurons are most active during wakefulness, particularly during periods of increased arousal or locomotor activity (Espana, 2004; Lu, 2010). Orexin/hypocretin neurons appear to be inhibited by the amines, and are at their highest level at the end of the day, possibly working to oppose the increasing sleep drive (Espana, 2004).

Dopamine is thought to have wake-promoting properties, but its' role in the sleep-wake cycle has been difficult to understand due to the lack of obvious change in dopaminergic firing rate throughout the sleep-wake cycle (Espana, 2004; Lu, 2010). Yet, extracellular levels of dopamine are elevated during wakefulness and dopamine receptor agonists increase waking while reducing non-REM and REM sleep (Espana, 2004). It has also been noted that patients using dopamine antagonists, such as antipsychotics, and patients with Parkinson's Disease (deficient in dopamine) are often sleepy (Espana, 2004; Lu, 2010). This supports likely wake-promoting properties of dopamine. 
Recently, there has been increasing evidence regarding the neurobiological overlap of sleep and ADHD (Owens, 2005). A proposed relationship for sleep disruption and ADHD is an altered pattern of melatonin secretion or responses to environmental cues such as light. Alternatively, common anatomical pathways may provide the link between sleep and ADHD. The reticular activating system and prefrontal cortex have been implicated in the regulation of both attention/arousal and sleep (Owens, 2005). The thalamus is thought to play a role in working memory and behavioral inhibition abnormalities in ADHD, and in the regulation of non-REM sleep (Owens, 2005). Additionally, aberrations in dopamine and norepinephrine signaling have been identified in both sleep disturbances and ADHD (Owens, 2005; Espana, 2004). The role of other neurotransmitters important in sleep such as histamine and acetylcholine in ADHD, if any, have not yet been identified. Although we do not fully understand the relationship between sleep and ADHD, there appears to be substantial overlap. We will further explore this relationship throughout this chapter.

\section{Typical sleep in children and adolescents}

As noted above, sleep is a complex process described as a rapidly reversible state of reduced responsiveness to the environment. Through basic processes inherent in sleep, our memories are consolidated, growth is optimized, and the next day we hopefully feel less sleepy, have restored energy and attention and the prospect of better learning and mood. During childhood and adolescence, sleep durations and patterns and other aspects such as associated behaviors change with normal development. Here we briefly review the architecture of sleep and how the patterns of sleep-wake cycles change with age (Owens, 2005; Mindell, 2010).

The architecture of sleep involves ultradian rhythms or cycles that consist of two sleep stages, non-REM and REM sleep. The duration of these ultradian cycles changes with development, being about 50 minutes in infancy and lengthening to adult levels (90-120 minutes) by school-age. It is typical for individuals to have a brief arousal at the end of these cycles, about 4 to 6 times during the sleep period. Non-REM sleep includes stage 1 or transitional sleep from which a person can be readily aroused, stage 2 which accounts for the majority of non-REM sleep and stage 3 or slow wave sleep (SWS), from which it is more difficult to arouse. REM sleep is characterized by an active EEG pattern and bursts of eye movements are a hallmark of this stage that includes dreaming. Non-REM sleep is more predominant early in the sleep period, about the first third, and REM sleep accounts for a greater percentage of sleep in the last third. Important biological functions are attributed to each sleep stage, for instance growth and neuroendocrine function for non-REM sleep and memory consolidation and learning for REM sleep. The stages of non-REM sleep develop in infancy and the relative percentage of SWS peaks during early childhood and declines by adolescence. In infancy, REM sleep accounts for about $50 \%$ of sleep. This declines during childhood and reaches adult levels (about 25-30\% of sleep) by adolescence (Mindell, 2010).

The overall duration and pattern of sleep changes with age and development (Iglowstein et al., 2003). Other factors also influence sleep patterns including (among others) child health and temperament, activities and regularity of family routines and cultural expectations. Typically, infants and toddlers sleep 11-13 hours across day and nighttime sleep and this declines to 9-10 hours by school age. While adolescents might self-describe needing less 
sleep, typical adolescents do best with about 9 to 9.25 hours. Naps account for 3-4 hours of total sleep for infants, distributed as $2-4$ a day and decline to 1 nap by about 18 months of age. Napping continues into toddler to preschool years; about $50 \%$ of children at age 3 years continue to nap, $25 \%$ at 4 years and $15 \%$ at 5 years. At school age, children are typically quite alert during the day and have little daytime sleepiness or napping unless driven by cultural preferences. At this age, daytime sleepiness would be a symptom deserving of further investigation, particularly in the context of learning, attention and behavioral problems. However, recent studies in this age group suggest that even in the absence of overt sleepiness, daytime behavioral concerns may indicate insufficient sleep duration or quality. By adolescence, the normal physiological phenomena of later sleep-wake cycles, called delayed sleep phase, typically predominates such that bedtimes and sleep onset times drift later, often by several hours. Concurrent early school start times set the stage for insufficient duration of night time sleep, typically 7 to 7.5 hours for many adolescents. In addition, teenagers have more variability in their sleep-wake patterns as they try to pay back their sleep debt on the weekend. Such irregular schedules add to the risk of sleep problems and chronic sleep deprivation affects several aspects of daytime functioning including attention, learning, and mood. Over half of adolescents report that they feel tired and sleepy during the day and about $25 \%$ reported falling asleep in school at least once a week (SAP, 2006). Sometimes caffeine will be used in the attempt to stay alert and result in further delay of sleep onset when consumed too close to bedtime.

It is also important to recognize that the ability of parents to report a sleep problem for their child also appears to be age-related. According to a recent national poll, about $16 \%$ of adolescents report having sleep problems; however, only about $7 \%$ of parents report problems with sleep for their teenagers (SAP, 2006). Parents of younger children may be more likely to be aware of the characteristics of their children's sleep and bring it up as a concern but not uniformly. Thus, it is important to inquire with children and adolescents directly as well as the parent when evaluating for sleep problems (Owens, 2000).

\section{Sleep disorders}

In the following section, we describe the medical and behavioral characteristics of several sleep disorders and review associated studies that examine daytime functioning, particularly related to attention, learning and behavior. The majority of pediatric research thus far has centered on the first two conditions described, sleep disordered breathing and restless legs or periodic limb movement disorder.

\subsection{Sleep Disordered Breathing}

The term sleep disordered breathing (SDB) represents a spectrum of disorders which includes at the severe end, obstructive sleep apnea (OSA). The SDB spectrum also includes other conditions such as, primary snoring (airflow causes airway vibration but no other observable abnormality), upper airway resistance syndrome (hypoventilation and increased intrathoracic pressure resulting in fragmented sleep but without frank apneas, or the cessation of breathing), and apnea due to central nervous system processes. OSA is marked by snoring and apnea, and accompanied by hypoxemia or oxygen desaturation. To determine whether the symptom of snoring is associated with periods of apnea or hypopnea (low airflow and associated oxygen desaturation) a polysomnogram or sleep study is 
needed. OSA is typically marked by repeated and sometimes prolonged periods of reduced or no airflow resulting in low oxygen delivery (hypoxia) to the brain and disrupted sleep (Mindell, 2010).

About $30 \%$ of children snore and about $3-4 \%$ have OSA. The parents of children with OSA might report hearing loud or heroic snoring and pauses in breathing, snorts or gasps. However, the symptoms of OSA may be less pronounced. Children with OSA may present with restless sleep, nocturnal sweating, unusual positions while sleeping (e.g., neck extended), morning headache and dry mouth. One risk for OSA emerges from processes of normal development. During preschool to early school age, children experience a relative increase of lymphoid tissue including tonsils and adenoids. When this increase outpaces the growth of the normal airway, a risk of airway obstruction occurs especially during periods of lower muscle tone, e.g., during sleep. Other factors also increase the risk of obstruction during breathing and include (among others), chronic nasal congestion, lower muscle tone due to medical conditions, oropharyngeal features, and obesity (Mindell, 2010; Hodges, 2011).

Growing concerns about SDB and the effect on day daytime functioning have fueled investigations about the relationship between ADHD and SDB in children presenting with one or the other condition or both. A number of methods have been used. Surveys have been conducted in general populations of children or in individuals suspected to have these specific disorders. Studies have also assessed for relationships between ADHD and SDB concurrently and prospectively as well as, before and after surgical intervention to remove tonsils and adenoids. Parents of children with an ADHD diagnosis were more likely to endorse symptoms of habitual snoring for their children than parents of non-snorers; $22 \%$ versus $12 \%$, respectively (Chervin, 2002). In addition, those children who were rated as having high SDB scores were more likely to describe ADHD symptoms of inattention and hyperactivity (Chervin, 1997). In a study of children ages two to thirteen years (at enrollment), those endorsed as habitual snorers at baseline were more likely to have hyperactive behavior four years later (Chervin, 2005). Early case studies reported ADHD symptoms in children referred for evaluation of SDB symptoms (Guilleminault C., 1981). In a study by Dillon et al, of children five to twelve years of age scheduled for adenotonsillectomy, nearly $37 \%$ had evidence of ADHD and disruptive behavior disorder (including oppositional and conduct disorder) and about 28\% had ADHD (Dillon, 2007). This study also assessed behavioral outcomes after adenotonsillectomy. Fifty percent of the children who met criteria for ADHD at baseline before adenotonsillectomy no longer did so after surgery (Dillon, 2007). In a review of sixteen studies, parents who reported higher SDB symptoms for their children also reported they had higher inattention and hyperactivity symptoms (Hodges, 2008; Cortese, 2009). Thus, there is substantial evidence supporting a relationship between ADHD and SDB.

In children with SDB, excessive daytime sleepiness is a common symptom that affects functioning related to attention and activity. Whereas tired or sleepy adolescents may report more problems staying awake, younger sleepy children may present with hyperactive and agitated behaviors (Hodges, 2011). In school-age children with SDB, time to fall asleep on structured nap tests (mean sleep latency test) was associated with the severity of SDB before adenotonsillectomy. One year after surgery; however, when SDB symptoms had improved, this association was no longer observed (Chervin, 2006; Gozal, 2001). In a meta-analysis 
review of 16 studies, daytime sleepiness was among the variables associated with ADHD. A recent study also found a significant relationship between daytime sleepiness and inattentive type ADHD (Cortese, 2009; Mayes, 2009). Other studies have demonstrated similar neurobehavioral outcomes related to SDB and/or excessive daytime sleepiness including impaired attention, tests of executive functioning, behavioral regulation and scores of intellectual functioning in some studies (Beebe, 2005; Owens, 2005; Beebe, 2004; Gottlieb, 2004). In many children with SDB, adenotonsillectomy results in improvements in neurobehavioral outcomes, and improvement in sleepiness is felt to play a role.

There does not appear to be a clear "dose-response" relationship between SDB and ADHD. In a community-based study, parents rated their 5-7 year old children for ADHD symptoms and a subset of the children underwent polysomnogram. OSA was observed for $26 \%$ of the children with mild ADHD symptoms versus 5\% for those with severe ADHD or no ADHD concerns. This study suggested that SDB might lead to mild ADHD symptoms but not explain more severe ADHD symptoms (O'Brien, 2003). Chervin suggests that the relationship between ADHD and SDB in at-risk children may be due to more subtle aspects of disordered breathing (Chervin, 2005). The mechanisms by which SDB and OSA in particular may relate to neurobehavioral sequelae have been proposed and involve the effect of sleep disturbance on the prefrontal cortex, sleep fragmentation, hypoxia, and hypercarbia (Beebe, 2005; Hodges, 2011). The relationship of such core factors with individual variables of risk are under investigation. Important individual variables include resilience, environmental context and demands, and the progression of these over time with development.

As noted above, there is substantial overlap between brain areas that regulate sleep, arousal and attention raising the possibility that sleep disruption may have direct effects on central nervous system functioning. In addition, sleep disruption during development suggests the possibility that structures such as the prefrontal cortex may sustain longer term neuroanatomic or functional alterations as a result of early sleep problems. Prospective studies will provide important contributions regarding the relationship between ADHD symptoms and SDB and these are ongoing currently.

\subsection{Restless leg syndrome and periodic limb movement disorder}

Restless legs syndrome (RLS), periodic limb movements of sleep (PLMS) and periodic limb movement disorder (PLMD) are overlapping conditions that may occur separately or together and affect sleep quality. There is evidence of a genetic basis for RLS with PLMS involving chromosome 6p.(Picchietti, 2008) Restless legs syndrome is a diagnosis made based on presenting clinical symptoms such as uncomfortable sensations (e.g, feeling things crawling or tingling) and the urge to move, both typically involving the lower limbs. RLS symptoms usually occur while sitting or lying down, toward evening hours, and the symptoms are typically relieved by movement. In children, the presentation of symptoms may be more variable and described differently, such as "shark bites" or "growing pains" for some children (Rajaram, 2004). Specific criteria for RLS were published in 2003 by NIH (Allen, 2003). While first observed in adults, RLS has been recognized in children for over fifteen years and is estimated to occur in about 2\% of children (Walters, 1994; Picchietti, 1998; Pichietti, 2007; Garcia-Borreguero, 2006; Picchietti, 2008). 
PLMS are brief, repetitive and regular stereotyped jerks during sleep, typically occurring at the lower extremities and lasting up to 5 seconds. PLMD requires a polysomnogram to make a diagnosis which requires five or more characteristic movements per hour (criteria for children and adolescents), associated with sleep disturbance (e.g., arousal) or effects on daytime functioning (e.g., fatigue), and no other primary sleep disorder reason for the PLMD. The prevalence of PLMD in the general population is not known. However, based on survey information, PLM symptoms are thought to affect about $8-12 \%$ of children (Picchietti, 2008). There is evidence that altered dopaminergic central nervous system functioning underlies RLS and PLMD for many individuals. In addition, MRI and autopsy studies have identified lower iron stores in the striatum and other central nervous system areas for adults affected with RLS or PLMD. Further, serum ferritin $<50 \mathrm{ng} / \mathrm{ml}$ has been associated with RLS symptoms or findings of PLMD and iron supplementation has been demonstrated to improve symptoms. Therefore, iron deficiency may be a treatable medical risk factor for RLS, PLMS and PLMD particularly associated with growing children, women during pregnancy and for individuals with chronic medical conditions (renal disease and leukemia) (Konofal, 2007; Mindell, 2010).

RLS and PLMD have been associated with daytime symptoms of ADHD. In a study of 143, two to eighteen year-old children attending child psychiatry or general pediatric clinics, parents indicated PLMS might be related to ADHD symptoms (Chervin, 1997). In a questionnaire study of 830 children two to thirteen years of age, about $4 \%$ of parents endorsed PLM symptoms for their children (Chervin, 2001). Picchietti and others looked at the occurrence of PLMD for children with or without ADHD symptoms. In their study, $26 \%$ of children with ADHD symptoms had PLMD, compared to 5\% of children who did not have ADHD symptoms (Picchietti, 1998). In a study comparing children referred for clinically defined ADHD versus two other groups, those identified as at risk for ADHD from a community survey and children without ADHD, those with clinically determined ADHD had higher PLMs than the other groups suggesting a greater risk for more active and disrupted sleep (O'Brien, 2003). In addition, in children with ADHD, serum ferritin less than $12 \mathrm{ng} / \mathrm{ml}$ was more prevalent in children with RLS symptoms (Oner, 2007). Thus, RLS, PLMS and PLMD appear to be related to daytime ADHD symptoms; however, but further work is needed to clarify the relationship and the role of iron specifically in the etiology and management.

\subsection{Other sleep disorders}

In the following section, other sleep disorders are described that affect sleep quality and/or duration but have fewer studies related to daytime behavioral consequences in children and adolescents. This is followed by a section describing the consequences of insufficient sleep in general.

\subsubsection{Behavioral insomnia of childhood}

Behavioral insomnia of childhood, the difficulty initiating and/or maintaining sleep due to a behavioral etiology, is very common, with a prevalence of $10-30 \%$. It is more often encountered in young children (Moore \& Meltzer, 2008). There are 2 types of Behavioral Insomnia of Childhood: Sleep Onset Association; and Limit Setting. Sleep Onset Association 
type of behavioral insomnia occurs when the onset of sleep is delayed in the absence of a certain item or circumstance. The child becomes dependent upon certain conditions being present during sleep onset, such as sucking on a pacifier or having another person close by. When the specific sleep onset conditions are met, sleep onset is quickly achieved. However, should the conditions not be met (i.e. the pacifier is on the floor, or mother is away) at sleep onset, then a struggle around getting to sleep may occur. In addition, when the child experiences a normal partial arousal during the night (commonly every 1-3 hours), the child who is used to certain conditions at bedtime will have difficulty returning to sleep if the conditions are no longer available. This circumstance of Behavioral Insomnia of Childhood, Sleep Onset Association type typically results in a night wakening and parent involvement to 'correct' or return the conditions for getting to sleep. Behavioral Insomnia of Childhood, Limit Setting type occurs when there are bedtime struggles. The child typically stalls or refuses to go to bed by requesting things such as a glass of water, or to go to the bathroom. When the caregiver has trouble setting and maintaining limits, the child's sleep onset is delayed as a consequence. However, when such limits are set consistently, the child is able to sleep quickly. Many children have a mixture of Sleep Onset Association and Limit Setting types. As children get older, they typically have less difficulty with Sleep Onset Association Insomnia as they are better able to get to sleep on their own and re-create their sleep onset conditions and return to sleep during the night. During those same developmental stages; however, children are working to become more independent and are testing limits set by their caregivers. Often this can result in greater difficulties with Limit Setting Insomnia with age (Moore \& Meltzer, 2008). Either type of behavioral insomnia can affect time to sleep onset, the continuity of nighttime sleep and the overall total amount of sleep achieved and therefore, the risk for daytime tiredness and associated sequelae for attention, learning and behavior.

\subsubsection{Delayed Sleep Onset in older children and adolescents}

\subsubsection{Delayed Sleep Phase Syndrome}

As children move toward adolescence, they typically begin to demonstrate a circadian preference for a later (delayed) sleep phase. If the preference for late sleep phase becomes problematic and interferes with the daytime functioning of the child or adolescent, it is referred to as having delayed sleep phase syndrome (DSPS). DSPS is common in adolescence with an estimated prevalence of $10 \%$ (Moore \& Meltzer, 2008). In DSPS, sleep onset and wake times are intractably later than socially acceptable (i.e., an adolescent who falls asleep at $1 \mathrm{am}$, and wakes at 10am although school starts at 8am), occur at approximately the same time daily, and there is little or no difficulty maintaining sleep after sleep onset has occurred. In DSPS, the timing of the sleep-wake cycle is the problem rather than the quality of sleep. There are often complaints of 'insomnia' when the child or adolescent attempts to go to sleep at an early time; however not when attempting to sleep at a later, desired time. Typically the child or adolescent has a very difficult time waking up at a required time, such as for school, and has decreased alertness in the morning. This can lead to frequent tardiness and/or absence from school. The child or adolescent frequently attempts to 'catch-up' on lost sleep by sleeping in to the late morning or afternoon on weekends. DSPS can significantly shorten sleep duration, increasing the risk for daytime tiredness and associated sequelae. 


\subsubsection{Psychophysiologic insomnia}

Primary or psychophysiological insomnia can also be responsible for sleep problems in children and adolescents. Insomnia is broadly defined as difficulty with onset, maintenance or non-restorative sleep. The following consensus statement has been developed to more specifically define pediatric insomnia: 'repeated difficulty with sleep initiation, duration, consolidation or quality that occurs despite age-appropriate time and opportunity for sleep and results in daytime functional impairment for the child and/or family' (Mindell, 2010). Primary insomnia is characterized by tension and learned sleep-preventing associations. Children and adolescents with primary or psychophysiological insomnia tend to respond to stress with somatic symptoms, and while trying to downplay the stress, end up increasing the stressfulness of their insomnia. Primary insomnia is rare in pre-pubertal children, but has a prevalence of 9 to $13 \%$ in adolescents (Mindell, 2010).

\subsubsection{Partial arousal parasomnias}

Partial arousal parasomnias are behaviors during sleep that occur primarily related to nonREM or slow wave sleep. These include confusional arousals, sleep walking, and sleep terrors. These partial arousals typically occur within a few hours of sleep onset and are fairly common in childhood, when the percent of non-REM sleep is greater compared to adulthood. Individuals with such partial arousal parasomnias do not recall the events that occur during sleep. Family history appears to increase the likelihood for both sleep walking and sleep terrors if other family members also experienced it. Confusional arousals are episodes where individuals are aroused but disoriented and may not fully awaken for up to 30 minutes. These occur in at least $17 \%$ of children. Sleep walking on a regular basis is also common in childhood, observed in about 15 to $20 \%$. Both confusional arousals and sleep walking typically begin in the preschool years. Confusional arousals tend to dissipate by early adolescence, whereas, for about $20 \%$ of affected individuals, sleep walking persists into adulthood. Sleep terrors are often more significant and distressing but primarily to the observer because the affected child can appear frightened and agitated. Sleep terrors occur in about 1 to $6 \%$ of children, with onset between preschool and preteen years and they typically subside by adolescence. These parasomnias can be triggered by inadequate or irregular sleep, illness, stress and other sleep problems such as SDB or PLMD. Parent and child education about the disorders, what they can do to lessen the risks for occurrence and assuring safety during episodes are the most important interventions. These behaviors do not disrupt sleep continuity on their own and therefore, uncomplicated partial arousal parasomnias are not typically associated with daytime behavioral sequelae like ADHD. However, a 2006 study from Taiwan suggested an association based on parental ratings (Shur-Fen Gau, 2006). In general, the presence of these parasomnias might indicate another sleep disorder that has been related to ADHD symptoms and might be the clue to look further for problems such as SDB, PLMD, or inadequate sleep.

\subsubsection{Sleep-related Rhythmic Movement Disorder}

Rhythmic movement disorder (RMD) is common in childhood, usually having onset in the first year of life and waning by early school age. This disorder includes various combinations of movements of the head, limbs, and trunk resulting in head rocking, head or body rolling, and head banging, among others and typically occur on transition to or from 
sleep or during sleep. It is typical for the movements to have a regular, rhythmic pattern. To meet criteria for RMD, the behavior must interfere with normal sleep, impair daytime functioning or cause bodily injury, and not be due to another disorder or use of medication. Most individuals do not require treatment for RMD as the risk of injury is low and it dissipates with age; however, protective surfaces might be needed for more significant cases (Hoban, 2003). Case studies have suggested RMD in children with ADHD and ADHD in children with RMD but studies to date are small (Walters, 2008).

\subsubsection{Night-time fears and nightmares}

As children get older, nighttime fears and nightmares become more frequent sleeping problems. Most children have nighttime fears, with peak ages from 3-6 years for both sexes, and in girls at school-age (Moore \& Meltzer, 2008). Nighttime fears are usually short-lived developmental phenomena and quite benign. At the peak age of nighttime fears at preschool-age, children are becoming more aware of the consequences of their actions and that they can really be hurt or affected by occurrences around them (Mindell, 2010). Typical nighttime fears change with developmental level, with younger children being more afraid of imaginary creatures such as monsters and older children being afraid of more realistic dangers such as a natural disaster or a burglar. Nightmares are also common in childhood, with approximately $75 \%$ of children experiencing at least one nightmare (Moore \& Meltzer, 2008; Mindell, 2010). Similar to nighttime fears, nightmares are a normal part of a child's development, and the content tends to vary by age. Young toddlers worry about being separated from their parents, and as children get older they incorporate imaginary and then realistic fears into their nightmares. Different from nighttime fears, nightmares typically occur during REM sleep (usually in the last third of the sleep period when there is a greater percentage of REM sleep), and can be triggered by sleep deprivation. Both nighttime fears and nightmares can be triggered or exacerbated by stress and anxiety. Consequences of nighttime fears or nightmares include delayed sleep onset and prolonged night awakenings, respectively and either affect the degree to which sleep is restorative for the affected individual.

\subsubsection{Enuresis}

Sleep enuresis is another possible cause of sleep disturbance in children. Uncomplicated or monosymptomatic sleep enuresis is characterized by recurrent, involuntary voiding occurring during sleep. Enuresis can occur in any stage of sleep, although most occur in the first half of the night (Mindell, 2010). It, too, follows the developmental trajectory of the child, with a greater proportion of younger children experiencing sleep enuresis. The majority of sleep enuresis episodes are primary sleep enuresis, in which the child has not yet developed control over voiding at night, and has not had a succession of dry nights. These children typically fail to respond to the sensation of bladder fullness or inhibit bladder contractions during the night. Spontaneous remission of sleep enuresis is common as children age; the approximate remission rate is $15 \%$ of affected individuals per year. The current prevalence estimates are $30 \%$ in 4 -year-olds, $10 \%$ of 6 -year-olds, $5 \%$ of 10 -year-olds and $3 \%$ of 12 -year-olds. Sleep enuresis is typically not diagnosed until age 5, and not treated until age 7 or 8 years. Primary enuresis is more prevalent in children with a family history of sleep enuresis, and also, those with ADHD. Secondary enuresis, in which the child 
previously has had control over their bladder at night (and has had a previous dry period of at least 6 months) and then develops sleep enuresis, does not occur as a part of typical development, and usually requires further diagnostic evaluation. It can be triggered by psychosocial stressors, medical problems such as urinary tract infections, chronic constipation, diabetes mellitus, a neurologic disorder, or other sleep disorders, such as obstructive sleep apnea or PLMD. Children with complicated or non-monosymptomatic sleep enuresis have day- and nighttime symptoms.

\section{Consequences of insufficient sleep}

As noted above for SDB and RLS/PLMD, poor sleep can have a great impact on daytime function of the child and other family members. Adults with poor sleep tend to appear tired during the day, yawning and falling asleep easily in inappropriate settings. However, the symptoms of sleepiness in children are often 'paradoxical' behavioral manifestations such as emotional lability, irritability, neurocognitive deficits and behavioral inhibition. These difficulties can cause problems at home, in school and in other community settings. Multiple parental reports (and some teacher reports) show increased incidence and severity of behavioral difficulties in children with sleep problems than those without (Fallone, 2002; Sadeh, 2002). More severe behavioral problems have been shown in children with shorter sleep duration (Fallone, 2002). Increased sleepiness or decreased sleep duration within the previous day have been associated with increased risk of accidental injury in children from preschool-aged through adolescence (Fallone, 2002). Insufficient sleep and/or sleepiness in adolescents have been associated with increased risk-taking behaviors (Moore \& Meltzer, 2008). Children with behavior problems are also more likely to have sleep problems by parental report (Fallone, 2002). Studies have shown improvement in these behavioral problems with improved sleep; however, not across all settings (Fallone, 2002). Lower academic achievement has also been associated with poor sleep in children, when compared to children with unimpaired sleep (Fallone, 2002). Additionally, adolescents who reported poor sleep were more likely to report social problems as well (Owens, 2008). An association between acute sleep restriction and poorer memory or lower IQ has not been found (Fallone, 2002; O'Brien, 2004). However, longer-term sleep disturbance has been linked to impaired memory and intelligence ( $\mathrm{O}^{\prime}$ Brien, 2004).

Children's sleep problems can also cause a significant amount of distress in the family. The impact of childhood sleep problems is related to the parents' sleep, especially if the parents' poor sleep leads to daytime fatigue or mood problems (O'Brien, 2004). Alternatively, improving the child's sleep, and by extension that of the rest of the family, can improve the functioning of all family members involved.

\section{Sleep in children with ADHD}

As noted previously in this chapter, sleep difficulties were part of the diagnostic criteria for ADHD in previous versions of the Diagnostic Statistical Manual, indicating a long-standing belief that sleep is problematic in children with ADHD. However, although the relationship between sleep and ADHD has been studied extensively over the past few decades very few objective differences have been found between the sleep of children with ADHD and children without ADHD. Yet, many subjective differences have been uncovered. 


\subsection{Sleep and ADHD: subjective differences}

There is little disagreement in the literature that parents of children with ADHD report poorer sleep for their children than parents of children without ADHD. O'Brien et. al found that $77 \%$ of children with significant symptoms of ADHD, and $70 \%$ of children with mild symptoms of ADHD were reported to have sleep disturbances while only $43 \%$ of children without ADHD symptoms were reported to have sleep problems ( $\mathrm{O}^{\prime}$ Brien, 2003). Parents of children with ADHD report more of the following than parents of children without ADHD: bedtime resistance; sleep-onset delay; anxiety; parasomnias; night wakings; daytime sleepiness; and shorter duration of sleep (Owens, 2000; Corkum, 2001; O'Brien, 2003; Silvestri et al., 2009; Gruber, 2009). Parents also report more snoring in children with ADHD compared with controls (Cortese, 2009). Children with and without ADHD tend to have morning arousal at the same time, but children with ADHD have a shorter reported sleep duration thought to be due to delayed sleep onset (Owens, 2005).

There are several possible explanations for these increased subjective complaints in children with ADHD. One hypothesis suggests that some of these are not sleeping problems per se, rather, behavioral problems in the context of a difficult parent-child relationship (Cortese, 2009; Corkum, 2001). Another hypothesis is that families of children with ADHD are more likely to have poor sleep hygiene (i.e., bedtime routines, sleeping environment), leading to more difficulties at bedtime (Cortese, 2009). Alternatively, children with ADHD may have symptoms throughout the day and evening, which creates bedtime difficulties even in the appropriate environment (Cortese, 2009; Gruber, 2009). Some children with ADHD may have a disorder of their sleep-wake schedule (i.e., delayed sleep phase syndrome or other disorder of circadian rhythm), and aren't able to fall asleep when they are expected to, which can lead to bedtime resistance (Gruber, 2009). Children with ADHD may also have co-morbid psychiatric disorders which contribute to bedtime difficulties (see below). Owens et. al found that parents of children with ADHD recognize sleep-onset difficulties as different from bedtime refusal. Other studies have drawn similar conclusions; parents are able to recognize the difference between unwillingness and inability to sleep (Blader et al., 1997). Stimulant medication is frequently used to treat ADHD in children and may have effects on their sleep. This will be addressed in a later section of this chapter.

\subsection{Sleep and ADHD: objective differences}

There is little agreement in the literature regarding objective differences in sleep in children with ADHD. Sleep in children with ADHD has been frequently studied but with small populations, and with conflicting results. Higher rates of obstructive sleep apnea (higher apnea-hypopnea index) have been found in children with ADHD (O'Brien, 2003; Cortese, 2009; Golan, 2004). Children with mild symptoms of ADHD are more likely to have obstructive sleep apnea than those with significant or no symptoms (O'Brien, 2003). Children with ADHD have also been found to have an increased REM latency and smaller percentage of sleep spent in REM (O'Brien, 2003, 2003; Silvestri et al., 2009; Busby, 1981). $\mathrm{O}^{\prime}$ Brien et al found a positive correlation between length of REM latency and impulsivity, inattention, cognition and hyperactive behaviors, and a negative correlation between REM latency and attention and executive functioning ( $\mathrm{O}^{\prime}$ Brien, 2003). Yet, other studies have shown an increase in percentage of REM sleep in children with ADHD (Golan, 2004) or decreased REM latency (Khan, 1982; Kirov et al., 2004), and still others have shown no differences in REM latency or percentage (Golan, 2004; Cortese, 2009). Increased periodic 
limb movements have been discovered in children with ADHD (Busby, 1981; O'Brien, 2003; Silvestri et al., 2009). Others have found decreased sleep efficiency, increased arousal index and increased daytime sleepiness in children with ADHD (Goraya et al., 2009; Cortese, 2009; O'Brien, 2003; Silvestri et al., 2009; Gruber, 2009; Golan, 2004). The hyperactivity in children with ADHD has been hypothesized as a compensatory mechanism for the increased daytime sleepiness related to poor duration and/or quality sleep. Despite these many studies, there is much more to be discovered concerning the sleep of children with ADHD.

One theory which addresses these conflicting differences in the sleep of children with ADHD is that there are different subsets of ADHD, some of which are associated with more sleeping problems. O'Brien et. al compared the sleep of children with ADHD referred to their sleep clinic, children with ADHD symptoms from the community and children without ADHD, and found that while all children with ADHD had some differences compared to the controls, the children who were referred also had greater nightmares, enuresis and witnessed apneas compared to the children with ADHD symptoms from the community group (O'Brien, 2003). They proposed that the children who were referred represent a different subset of children with ADHD. Additionally, differences have been found, in some cases, between the sleep of children with ADHD inattentive subtype and combined subtype, with more differences in sleeping patterns found between children with combined subtype ADHD and typically developing children (Gruber, 2009; Mayes, 2009).

Co-morbid psychiatric disorders are common in children with ADHD, and are thought to contribute to problems with sleep. Children with ADHD and anxiety or depression were found to have more sleeping problems than those without, although children with comorbid oppositional defiant disorder (ODD) were not found to have increased sleeping problems (Mayes, 2009). Sleep problems have been shown to have a weaker relationship with ADHD after controlling for co-morbid anxiety, depression or disruptive behavior disorders (Mick, 2000). However, some of the studies previously discussed in this section found differences in sleep in children with ADHD without co-morbid psychiatric disorders compared to typically developing children.

\section{Medical treatment for ADHD and sleep problems}

\subsection{Psychostimulant medications for ADHD and effects on sleep}

Psychostimulant medication, the first-line treatment for ADHD, has often been cited as causing sleeping disturbances in this population. However, as discussed in previous sections, there is a complicated relationship between ADHD and sleep. Some have suggested that stimulant medication causes sleep disturbances in children and adolescents with ADHD. Some studies of stimulant medication have supported this, but others have shown no change or improvements in sleep in children and adolescents treated with psychostimulant medication, (Galland et al., 2010; Mick, 2000; Barkley et al., 1990; Giordani, 2008; O'Brien, 2003; Kim, 2010; Giblin \& Strobel, 2010).

Regarding studies where the use of psychostimulant medication has been associated with poor sleep, in a study by Mick et. al, there was a trend towards children with ADHD having more sleep disorders and when multiple confounding variables were accounted for, they found a relationship between the use of stimulant medication and poor sleep (Mick, 2000). Children with ADHD treated with psychostimulant medication were more likely than 
controls to be reported as a restless sleeper, waking during the night, talking in their sleep, afraid of sleeping in the dark and going to the bathroom during the night (Mick, 2000). Parents have also reported more difficulty with insomnia in children with ADHD treated with psychostimulants (Barkley et al., 1990). Several objective studies have also shown changes in sleep with psychostimulant medication. EEG studies have shown increased REM onset latency and of stage 1 and 2 sleep with a resultant decrease in time spent in REM and stage 3 sleep after nocturnal administration of a psychostimulant (Chatoor, 1983). Polysomnography studies showed no significant difference in sleep timing, duration or efficacy between children with ADHD off of medication for 48 hours and control children (Galland et al., 2010). However, when the children with ADHD had taken their dose of psychostimulant medication, they had a longer sleep latency and woke earlier in the morning, resulting in a shorter sleep duration in comparison to control children (Galland et al., 2010). Sleep architecture was not altered by the medication (Galland et al., 2010). Galland et. al observed that their study, and others that had found increased sleep onset latency on psychostimulant treatment, were designed such that the comparisons between methylphenidate and placebo were within-subject. They postulate that this may indicate that the individual differences of the effects of psychostimulant medication on sleep may be more important than larger group differences (Galland et al., 2010).

Another hypothesized factor is that the increased reported difficulties with sleep in children with ADHD treated with psychostimulant medication may be the result of the psychostimulant medication wearing off and/or causing a 'rebound' effect. This rebound effect can lead to an apparent increased arousal and hyperactivity. This led to the idea that some children may benefit from an additional late afternoon or early evening dose of psychostimulant medication. An additional late afternoon (4pm) dose was shown to improve behavior in 12 psychiatrically hospitalized children with ADHD (Kent et al., 1995). Low-dose (10mg) and high-dose (15mg) methylphenidate and placebo were given at 4pm, with little effect on the sleep onset in the children (Kent et al., 1995). When receiving the high-dose methylphenidate, children did have an increased sleep onset latency (Kent et al., 1995). Notably, the increased sleep onset latency in children on the higher dose of methylphenidate was similar to that of children on the placebo (Kent et al., 1995). A similar study tested the effect of twice-daily dosing to thrice-daily dosing of methylphenidate in children with ADHD, and found that there were no differences in sleep duration between the two dosing regimens (Stein, 2001). However, there was a trend toward decreased sleep duration in the thrice-daily dosing compared to placebo on parental ratings and actigraphic measurements (Stein, 2001). Sleep onset latency did not differ significantly across the dosing protocols (including placebo) (Stein, 2001).

Other recent studies, have confirmed the relationship of ADHD with poor sleep, but demonstrated little association psychostimulant medication to poorer sleep in children with ADHD. Children with ADHD were found to have more sleep disturbances than those without ADHD, irrespective of their medication status (O'Brien, 2003). The use of psychostimulant medication was not found to have an association with poor sleep ( $\mathrm{O}^{\prime}$ Brien, 2003). Children with ADHD treated with psychostimulant medication tended to have longer REM onset latency, however this did not reach statistical significance (O'Brien, 2003).

Increased sleep disturbances have not been found in children treated with sustained release preparations of psychostimulants (Kim, 2010; Giblin \& Strobel, 2010). Osmotic-controlled 
release oral delivery system (OROS) methylphenidate was found to decrease the number of night arousals (parasomnias) in children with ADHD, but not alter sleep onset latency on either subjective or objective measures (Kim, 2010). However, children who reported subjective sleep difficulties during treatment with OROS methylphenidate had increased sleep onset latency, sleep onset delay and bedtime resistance when compared to those without subjective sleep complaints. This again, may indicate that the individual's response to stimulant medication may be the most important factor (Kim, 2010). Lisdexamfetamine was also shown to decrease nighttime arousals, and did not negatively impact sleep in children with ADHD (Giblin \& Strobel 2010). The decreased nighttime arousals may suggest more consolidated sleep in children treated with psychostimulants.

Therefore, the use of psychostimulant medications has been associated with poor sleep in children with ADHD in some studies; however the exact relationship remains unclear. Individuals with sleep complaints while on psychostimulant medications have been noted to have increased sleep disturbance. Perhaps it is best to consider each patient individually when assessing for adverse effects of treatment. It may be that for the majority of patients, treatment with psychostimulant medication does not interfere with sleep, but in those reporting worse sleep, the medication does play a role in sleep disturbances.

\subsection{Non-psychostimulant Medications for ADHD and effects on sleep}

In 2002, the US Food \& Drug Administration (FDA) approved the non-stimulant, atomoxetine for use in children with ADHD. Greater clinical improvement is typically attained with psychostimulant medication; however atomoxetine can be good alternative medication to use when a psychostimulant medication is not tolerated or cannot be used (Newcorn et al., 2008). When compared with thrice-daily dosing of methylphenidate, twicedaily atomoxetine was found to have decreased sleep onset latency, and increased sleep duration (Sangal, 2004). Treatment with twice-daily atomoxetine and thrice-daily methylphenidate resulted in decreased interrupted sleep; however, treatment with methylphenidate led to a larger decrease in interrupted sleep (Sangal, 2004). Children reported an easier time awakening in the mornings and falling asleep at night while taking atomoxetine (Sangal, 2004). The most common sleep-related adverse effect reported from atomoxetine is somnolence (Kratochvil et al., 2011; Cheng et al., 2007; Newcorn et al., 2008).

Alpha-agonists such a clonidine and guanfacine have been used to treat both the behavioral and sleep problems of ADHD. Clonidine has been helpful in treating sleeping problems in children with ADHD (Plizka, 2007). Trials of long acting clonidine (with and without the use of psychostimulants) have shown that somnolence and/or fatigue are the major sleeprelated adverse effect of treatment (Biederman et al., 2008; Kollins et al., 2011). However, Biederman et. al showed that this is usually a transient effect (Biederman et al., 2008).

\subsection{Medications for sleep problems in children with ADHD}

As discussed extensively in this chapter, sleeping disturbances are frequently associated with ADHD. Some of these sleep disturbances can be related to anatomic disorders, such as sleep-disordered breathing or perhaps an adverse effect of psychostimulant medication. However, in many cases, a modifiable cause is not identified that results in a medical treatment for the sleep disturbance. In fact, a large Netherlands study of children with 
ADHD on stimulant medication found that over $10 \%$ of the children were taking melatonin, presumably for sleep problems (Faber et al., 2006). Melatonin has been shown to decrease sleep onset latency in children with ADHD (not on medication) with chronic sleep-onset insomnia (Van der Heijden et al., 2006). Despite this improved sleep onset latency, there was not significant effect (positive or negative) on the children's behavior, cognition or quality of life (Van der Heijden et al., 2006). In follow-up of this study, approximately 3 years later, the majority of children remained on melatonin, and their parents thought it was an effective treatment (Hoebert et al., 2009). Parents reported that the melatonin improved their children's daytime behavior (Hoebert et al., 2009). A literature review confirmed that children with ADHD and insomnia showed improvement in regards to sleep onset latency when taking melatonin (Bendz \& Scates, 2010). However, these results are limited as there are few studies, and most of them have small sample sizes. Zolpidem has also been evaluated for treating sleep disturbances in children and adolescents with ADHD (Blumer et al., 2009). Zolpidem did not decrease sleep onset latency, nor improve sleep efficiency or nocturnal awakenings (Blumer et al., 2009). There was a trend toward improving behavioral symptoms, particularly in the adolescents; however, this did not reach statistical significance (Blumer et al., 2009).

\section{Clinical application}

In this section, we describe two clinical cases examples where ADHD evaluation might be complicated by sleep concerns. The purpose is to highlight several concepts regarding development and sleep.

\subsection{Younger child}

Alex, a 7-year-old boy, presented to his primary care physician's office with his mother due to problematic behavior at school. His mother notes that he's always been a busy and active child. Over the past few years, she's had some difficulty with his behavior at home, noting that he had frequent temper tantrums as a toddler and preschool-aged child, but the parents thought his behavior was manageable. However, last year in kindergarten Alex's teacher also expressed concern about his behavior and this has increased with his first grade teacher this year. He has been having difficulty staying seated with the rest of his class during story time and with staying in line with his class when they leave the classroom. He has also recently hit a classmate over a minor disagreement. He typically gets along with other children, and mother notes that he has two best friends, with whom he likes to ride bikes. There was no history of problems at birth or with development. He has no chronic medical concerns, has not had hospitalization or surgery and has not had significant injuries. He is involved in Boy Scouts and sports outside of school.

On review of systems, Alex's mother notes that his sleep schedule is typically uniform throughout the week. He goes to bed around 8 PM on weeknights, and wakes up at 7 AM for school. On the weekends, he tends to go to bed around 8:30 PM, and wakes at 7 AM on his own. He tends to fall asleep approximately 30-45 minutes after his bedtime. He does not appear tired in the morning or throughout the day, and does not nap, nor fall asleep unintentionally. His mother does struggle to put him to bed most nights, noting that he seems "to do anything to avoid sleeping". He frequently asks for another story, and glass of water. Alex's mother also notes that he snores quite loudly; she can hear him snoring from 
her bedroom when his door is closed. She hasn't noted any pauses in breathing. He sweats during sleep frequently, requiring his mother to change the sheets during the night approximately once a week. He has been dry at night for the past three months, and prior to that he had sleep enuresis approximately once every two weeks. Alex's mother and older brother have ADHD, and his maternal grandfather was recently diagnosed with obstructive sleep apnea. He does not have any family history of learning disability or mood disorder. His physical exam was notable for mouth breathing and $3+$ tonsils.

Alex's sleep concerns raise questions about multiple sleep problems. One such problem is sleep disordered breathing, common in early school-age children. Alex is at a peak age for increased lymphoid hypertrophy, which can cause a relative narrowing of the airway during sleep. His bedtime resistance could suggest behavioral insomnia of childhood, limit setting type, with inadequate limit-setting by his mother or his negative behavior may be the result of tiredness made worse by the poor quality sleep due to sleep disordered breathing. Alex's duration of sleep is likely appropriate for his age; however the quality is likely disturbed and affecting his daytime functioning.

To evaluate further, an overnight polysomnography was performed, which demonstrated obstructive sleep apnea. Conners rating scales from both parents and his first grade teacher endorsed problems with attention, hyperactivity and impulsivity for age and gender.

Alex was evaluated by a pediatric otolaryngologist who recommended an adenotonsillectomy, which was subsequently performed. Three months after his surgery, Alex's mother noted significant improvements in his snoring, now only infrequently and that he no longer sweats at night, and has remained dry overnight. However, he has remained very active and 'on the go' and while his behavior problems at school had improved somewhat, he continued to have difficulties. His primary physician initiated a trial of short-acting stimulant medication, to which Alex responded quite well. Alex's presenting concerns seemed to be related to both his sleep problems and underlying ADHD.

\subsection{Early adolescent}

Susie, a 13-year-old female, presents to her primary doctor accompanied by her mother for concerns regarding poor school performance. Mother states Susie has had longer term concerns about being fidgety and distractible but had always been able to keep pace with her peers until 7 th grade. There were no academic concerns in elementary school and grades continued to be adequate, although in retrospect, drifted downward in 6th grade. In 7th grade she had more trouble; she forgot to turn in assignments, seemed disorganized and didn't follow through on directions at school, as well as, at home. In 8th grade this year, she is close to failing. Teachers state her test performance has been good, but the frequently missing assignments and little engagement in classroom discussions have pulled down her grades. In addition, they report she has been prone to napping in the first-hour math class. There is no history of problems at birth or with development. She has no chronic medical concerns and has not had significant injuries. She started menses at about 10 years of age. She is active with sports and music for school, participating in swimming and playing cello throughout the year. Her group of friends has been stable. She describes a very busy school schedule and that she is concerned about doing well. 
On review of systems, Susie states that on weekends, she typically goes to sleep about midnight and will get up about 10 to 11 AM on her own. During the school week, she tries to go to bed at 10 PM but "can't get to sleep for hours". She needs to be up by 6 AM for school. She describes feeling uncomfortable at sleep onset due to her legs feeling restless and thinking about the next school day. Mother has not had concerns about Susie snoring nor mouth breathing in the past. She recently slept in the same room on a vacation and did not hear audible mouth breathing but did notice that Susie seemed to toss a turn quite a bit during sleep. Susie had occasional sleep walking when younger but not in the last four years. Susie and her family are vegetarian and she doesn't usually take vitamins. Paternal family members have had ADHD and restless legs but no history of learning disability, anxiety or sleep disordered breathing. There were no significant physical exam findings.

Susie's sleep concerns raise a question about several sleep problems. One is delayed sleep phase syndrome, a common tendency among adolescents for the sleep-wake schedule to drift later. Susie's later sleep-wake cycle, when coupled with her school schedule, increases the risk for problems with sleep initiation and getting up in time for school. Her restlessness at bedtime and through the night, as well as the sensations at the lower extremities at bedtime suggest restless legs syndrome. She is at risk for iron deficiency, associated with RLS/PLMD, due to the less dietary iron, growth due to adolescence and losses due to early menarche. In addition, Susie's worries about doing well may add to her risk for insomnia. Altogether, Susie's duration and quality of sleep are likely disturbed and in turn, affecting daytime functioning through potentially direct effects related to RLS and indirectly through chronic sleep deprivation. Her daytime sleepiness is an indication that the sleep she is getting isn't enough. The parent has had a long-standing concern about some ADHD symptoms but the onset is later than typical.

To evaluate Susie further, a sleep log was obtained to assess sleep duration and the stability of sleep-wake pattern. Iron studies were obtained and showed a serum ferritin of 10 , borderline low serum iron but no anemia. Conners rating scales from both parents and two teachers endorsed problems with attention and executive functioning but all other scales (including hyperactive-impulsive domains) were within normal limits for age and gender.

Susie was recommended to begin an iron supplement for the mild iron deficiency. In addition, Susie worked with the doctor to regularize her sleep-wake schedule between weekday and weekend. Susie also adjusted her daytime schedule so that she felt better able to meet her commitments for school, homework, practice times and friends. After three to four months, repeat iron studies showed correction of iron status and improved RLS symptoms. She was adhering to the new schedule and getting to sleep more easily. Conners rating scales and interview at follow up did not endorse ADHD concerns and teachers reported improved school performance. Taken together, Susie's presenting concerns seemed more likely related to sleep problems than ADHD at this time, but longer term follow up was recommended to assure she remained on track.

\section{Conclusion}

In this chapter, we have reviewed the relationship between ADHD and sleep disorders with the purpose of highlighting the importance of evaluating sleep problems when children and adolescents present for evaluation of ADHD. Studies have suggested that many 
practitioners do not routinely screen for sleep problems in general or for specific conditions like SDB in particular (Chervin, 2000; Chervin, 2001; Blunden, 2004). In one study in a general pediatric clinic, 830 parents of children ages two to thirteen years of age completed the Pediatric Sleep Questionnaire (PSQ), a validated survey of a number of medical and behavioral problems of sleep in children (Chervin, 2000). The parents of 86 children endorsed a sleep problem for their child and 44 of them (about $5 \%$ of the total number) endorsed symptoms of sleep disordered breathing. On a retrospective chart review of these children, less than $11 \%$ ( 5 of 44 ) had documentation that the symptoms were discussed (Chervin, 2001). Other studies have also called attention to the importance of screening about sleep problems in primary care settings (Blunden, 2004; Fallone, 2002).

\begin{tabular}{|c|c|c|c|}
\hline & $\begin{array}{l}\text { Toddler/preschool } \\
\text { (2-5 years) }\end{array}$ & $\begin{array}{l}\text { School-aged } \\
\text { (6-12 years) }\end{array}$ & $\begin{array}{c}\text { Adolescent } \\
\text { (13-18 years) }\end{array}$ \\
\hline $\begin{array}{l}\text { 1. Bedtime } \\
\text { problems }\end{array}$ & $\begin{array}{l}\text { Does your child have } \\
\text { any problems going to } \\
\text { bed? Falling asleep? }\end{array}$ & $\begin{array}{l}\text { Does your child have any } \\
\text { problems at bedtime? } \\
\text { (Parent) Do you have any } \\
\text { problems going to bed? } \\
\text { (Child) }\end{array}$ & $\begin{array}{c}\text { Do you have any } \\
\text { problems falling } \\
\text { asleep at bedtime? } \\
\text { (Child) }\end{array}$ \\
\hline $\begin{array}{l}\text { 2. Excessive } \\
\text { daytime } \\
\text { sleepiness }\end{array}$ & $\begin{array}{l}\text { Does your child seem } \\
\text { overtired or sleepy a lot } \\
\text { during the day? Does } \\
\text { she still take naps? }\end{array}$ & $\begin{array}{c}\text { Does your child have } \\
\text { difficulty waking in the } \\
\text { morning, seem sleepy } \\
\text { during the day or take } \\
\text { haps? (Parent) Do you feel } \\
\text { tired a lot? (Child) }\end{array}$ & $\begin{array}{l}\text { Do you feel sleep a } \\
\text { lot during the day? } \\
\text { In school? While } \\
\text { driving? (Child) }\end{array}$ \\
\hline $\begin{array}{l}\text { 3. Awakenings } \\
\text { during the } \\
\text { night }\end{array}$ & $\begin{array}{c}\text { Does your child wake } \\
\text { up a lot at night? }\end{array}$ & $\begin{array}{c}\text { Does your child seem to } \\
\text { wake up a lot at night? } \\
\text { Any sleepwalking or } \\
\text { nightmares? (Parent) Do } \\
\text { you wake up a lot at } \\
\text { night? Have trouble } \\
\text { getting back to sleep? } \\
\text { (Child) }\end{array}$ & $\begin{array}{l}\text { Do you wake up a } \\
\text { lot at night? Have } \\
\text { trouble getting back } \\
\text { to sleep? (Child) }\end{array}$ \\
\hline $\begin{array}{l}\text { 4. Regularity } \\
\text { and duration } \\
\text { of sleep }\end{array}$ & $\begin{array}{c}\text { Does your child have a } \\
\text { regular bedtime and } \\
\text { wake time? What are } \\
\text { they? }\end{array}$ & $\begin{array}{c}\text { What time does your child } \\
\text { go to bed and get up on } \\
\text { school days? Weekends? } \\
\text { Do you think he/she is } \\
\text { getting enough sleep? } \\
\text { (Parent) }\end{array}$ & $\begin{array}{l}\text { What time do you } \\
\text { usually go to bed on } \\
\text { school nights? } \\
\text { Weekends? How } \\
\text { much sleep do you } \\
\text { usually get? (Child) }\end{array}$ \\
\hline 5. Snoring & $\begin{array}{c}\text { Does your child snore a } \\
\text { lot or have difficulty } \\
\text { breathing at night? }\end{array}$ & $\begin{array}{c}\text { Does your child have loud } \\
\text { or nightly snoring or any } \\
\text { breathing difficulties at } \\
\text { night? (Parent) }\end{array}$ & $\begin{array}{l}\text { Does your teenager } \\
\text { snore loudly or } \\
\text { nightly? (Parent) }\end{array}$ \\
\hline
\end{tabular}

Source: Owens, J. and Dalzell, V. “Use of the 'BEARS' sleep screening tool in a pediatric continuity clinic: a pilot study." Sleep Medicine: 6 (2005) 63-69, used with permission

Table 1. BEARS Sleep Screening Algorithm 
A screening tool, the BEARS was developed by Owens et. al., and consists of five sleeprelated areas to screen at primary care visits. After implementing this instrument in a primary care setting, significantly more sleep issues were documented and sleep problems identified by the practitioners (Owens \& Dalzell, 2005).

The term "BEARS" stands for:

- $\quad$ B - Bedtime problems

- $\quad$ E - Excessive daytime sleepiness

- A - Awakenings during the night

- $\quad \mathrm{R}$ - Regularity of sleep/wake cycles and average sleep duration

- $\quad$ S - Snoring

In conclusion, the relationship between ADHD and sleep disorders in children and adolescents can make evaluation of ADHD challenging. However, a methodical and thorough evaluation that recognizes expected and unexpected developmental features related to sleep will help to assure proper and timely identification and management of both ADHD and disorders of sleep.

\section{References}

2004 Sleep in America Poll Summary of Findings. 2004. Washington DC: National Sleep Foundation.

2006 Sleep in America Poll, Teens and Sleep, Summary of Findings. 2006. Washington DC: National Sleep Foundation.

Allen, R.P., Pichietti, D., Hening, W.A., et al. 2003. Restless legs syndrome: Diagnostic criteria, special considerations, and epidemiology. A report from the restless legs syndrome diagnosis and epidemiology workshop at the National Institutes of Health. Sleep Medicine 4:101-119.

Association, American Psychiatric. 2000. Diagnostic and statistical manual of mental disorders (4th ed., text rev.). 4 ed. Washington, DC.

Association", "American Psychiatric. 1987. Diagnostic and Statistical Manual of Mental Disorders, Third Edition, Revision. Washington DC: American Psychiatric Association.

Barkley, RA, McMurray MB, Edelbrock CS, Robbins K 1990. Side Effects of Metlyiphenidate in Children With Attention Deficit Hyperactivity Disorder: A Systemic, PlaceboControlled Evaluation. Pediatrics 86 (2):184-192.

Beebe, D. W. . 2005. Neurobehavioral effects of obstructive sleep apnea: an overview and heuristic model. Current Opinion in Pulmonary Medicine 11:494-500.

Beebe, D. W., Wells, C. T., Jeffries, J., Chini, B., Kalra, M., Amin, R. . 2004. Neuropsychological effects of pediatric obstructive sleep apnea. Journal of the International Neuropsychological Society 10:962-975.

Bendz, LM, Scates AC 2010. Melatonin Treatment for Insomnia in Pediatric Patients with Attention-Deficit/Hyperactivity Disorder. Ann Pharmacother 44 (1):185-191.

Biederman, J, Melmed RD, Patel A, McBurnett K, Konow J, Lyne A, Scherer N and for the SPD503 Study Group. 2008. A Randomized, Double-Blind, Placebo-Controlled Study of Guanfacine Extended Release in Children and Adolescents With Attention-Deficit/Hyperactivity Disorder. Pediatrics 121 (1):e73-e84. 
Blader JC, Koplewicz HS, Abikoff H, Foley C 1997. Sleep Problems of Elementary School Children: A Community Survey. Arch Pediatr Adolesc Med 151 (5):473-480.

Blumer JL, Findling RL, Shih WJ, Soubrane C, Reed, MD 2009. Controlled Clinical Trial of Zolpidem for the Treatment of Insomnia Associated With Attention-Deficit/ Hyperactivity Disorder in Children 6 to 17 Years of Age. Pediatrics 123 (5):e770e776.

Blunden, S. Lushington, K., Lorenzen, B., Ooi, T., Fung, F. Kennedy, D. . 2004. Are sleep problems under-recognised in general practice? Arch Dis Child 89:708-712.

Busby, K., Firestone, P., Pivik, R.T. 1981. Sleep Patterns in Hyperkinetic and Normal Children. Sleep 4 (4):366-383.

Chatoor, I., Wells, K., Conners, K., Seidel, W., Shaw, D. 1983. The Effects of Nocturnally Administered Stimulant Medication on EEG Sleep and Behavior in Hyperactive Children. Journal of American Academy of Child Psychiatry 22 (4):337-342.

Cheng J, Chen R, Ko J, Ng E 2007. Efficacy and safety of atomoxetine for attentiondeficit/hyperactivity disorder in children and adolescents-meta-analysis and meta-regression analysis. Psychopharmacology 194 (2):197-209.

Chervin, R. D., Archbold, K. H., Dillon, J. E., Panahi, P., Pituch, K. J., Dahl, R. E., Guilleminault, C. . 2002. Inattention, Hyperactivity, and Symptoms of SleepDisordered Breathing. Pediatrics 109 (3):449-456.

Chervin, R. D., Archbold, K. H., Panahi, P, Pituch, K. J. . 2001. Sleep Problems Seldom Addressed at Two General Pediatric Clinics. Pediatrics 107 (6):1375-1380.

Chervin, R. D., Dillon, J. E. Bassetti, C. Ganoczy, D. A., Pituch, K. J. . 1997. Symptoms of Sleep Disorders, Inattention, and Hyperactivity in Children. Sleep 20 (12):1185-1192.

Chervin, R. D., Hedger, K., Dillon, J. E. Pituch, K. J. . 2000. Pediatric Sleep Questionnaire (PSQ): validity and reliability of scales for sleep-disordered breathing, snoring, sleepiness, and behavioral problems. Sleep Medicine 1:21-32.

Chervin, R. D., Ruzicka, D. L., Archbold, K. H., Dillon, J. E. . 2005. Snoring Predicts Hyperactivity Four Years Later. Sleep 28 (7):885-890.

Chervin, R. D., Weatherly, R. A., Ruzicka, D. L., Burns, J. W., Giordani, B. J., Dillon, J. E., Marcus, C. L., Garetz, S. L., Hoban, T. F., Guire, K. E. 2006. Subjective sleepiness and polysomnographic correlates in children scheduled for adenotonsillectomy vs. other surgical care. Sleep 29 (4):495-503.

Chervin, R.D. 2005. Attention deficit, hyperactivity, and sleep disorders. In: Sheldon SH, Ferber R, Kryger Meir H, editors. Principals and Practice of Pediatric Sleep Medicine. 1 ed. Elsevier Saunders; . Principles and Practice of Pediatric Sleep Medicine: 161-169.

Committee on Quality Improvement, Subcommittee on Attention-Deficit/Hyperactivity Disorder. 2000. Clinical Practice Guideline: Diagnosis and Evaluation of the Child With Attention-Deficit/Hyperactivity Disorder. Pediatrics 105 (5):1158-1170.

Conners K, Sitarenios G, Parker JDA, Epstein JN 1998. The Revised Conners' Parent Rating Scale (CPRS-R): Factor Structure, Reliability, and Criterion Validity. Journal of Abnormal Child Psychology 26 (4):257-268.

Conners K, Sitarenios G, Parker JDA, Epstein JN 1998. Revision and Restandardization of the Conners Teacher Rating Scale (CTRS-R): Factor Structure, Reliability, and Criterion Validity. Journal of Abnormal Child Psychology 26 (4):279-291. 
Corkum, P., Tannock, R., Moldofsky, H., Hogg-Johnson, S., Humphries, T. 2001. Actigraphy and Parental Ratings of Sleep in Children with Attention-Deficit/Hyperactivity Disorder (ADHD). Sleep 24 (3):303-312.

Cortese, S., Faravone, S. V., Konofal, E., Lecendreux, M. 2009. Sleep in Children With Attention-Deficit/Hyperactivity Disorder: Meta-Analysis of Subjective and Objective Studies. American Academy of Child and Adolescent Psychiatry 48 (9):894908.

Curatolo P, Paloscia C, D’Agati E, Moavero R, Pasini A 2009. The neurobiology of attention deficit/hyperactivity disorder. European Journal of Paediatric Neurology 13 (4):299304.

Dahl RE 1996. The regulation of sleep and arousal: Development and psychopathology. Development and Psychopathology 8 (01):3-27.

Del Campo N, Chamberlain SR, Sahakian BJ, Robbins TW 2011. The Roles of Dopamine and Noradrenaline in the Pathophysiology and Treatment of AttentionDeficit/Hyperactivity Disorder. Biological Psychiatry 69 (12):e145-e157.

Dillon, J.E. Blunden, S. Ruzicka, D.L. Guire, K.E. Champine, D. Weatherly, R.A. Hodges, E.K. Giordani, B.J. Chervin, R.D. 2007. DSM-IV Diagnoses and Obstructive Sleep Apnea in Children Before and 1 Year After Adenotonsillectomy. American Academy of Child and Adolescent Psychiatry 46 (11):1425-1436.

Durston, S. Tottenham, N. Thomas K.M. Davidson, M.C. Eigsti, I. Yang, Y. Ulug, A.M. Casey, B.J. 2003. Differential Patterns of Striatal Activation in Young Children with and without ADHD. Society of Biological Psychiatry 53:871-878.

Espana, RA; Scammell TE. 2004. Sleep neurobiology for the clinician. In Sleep

Faber A, Kalverkijk LJ, de Jong-van den Berg LTW, Hugtenburg JG, Minderaa RB, Tobi H 2006. Parents Report on Stimulant-Treated Children in the Netherlands: Initiation of Treatment and Follow-Up Care. Journal of Child and Adolescent Psychopharmacology 16 (4):432-440.

Fallone, G., Owens, J. A., Deane, J. . 2002. Sleepiness in children and adolescents: clinical implications. Sleep Medicine Reviews 6 (4):287-306.

Faraone, S. V., Biederman, J. . 1998. Neurobiology of Attention-Deficit Hyperactivity Disorder. Society of Biological Psychiatry 44:951-958.

Faraone, S. V., Perlis, R. H., Doyle, A. E., Smoller, J. W., Goralnick, J. J., Holmgren, M. A., Sklar, P. . 2005. Molecular Genetics of Attention-Deficit/Hyperactivity Disorder. Society of Biological Psychiatry 57:1313-1323.

Fuller PM, Gooley JJ, Saper CB 2006. Neurobiology of the sleep-wake cycle: sleep architecture, circadian regulation, and regulatory feedback. Journal of Biological Rhythms 21 (6):482(12).

Galland BC, Tripp EG, Taylor BJ 2010. The sleep of children with attention deficit hyperactivity disorder on and off methylphenidate: a matched case-control study. Journal of Sleep Research 19 (2):366-373.

Garcia-Borreguero, D., Egatz, R., Winkelmann, J., Berger, K. 2006. Epidemiology of restless legs syndrome: The current status. Sleep Medicine Reviews 10:153-167.

Giblin JM, Strobel AL 2010. Effect of Lisdexamfetamine Dimesylate on Sleep in Children With ADHD. Journal of Attention Disorders.

Giordani, B., Hodges, E. K., Guire, K. E., Ruzicka, D. L., Dillon, J. E., Weatherly, R. A., Garetz, S. L., Chervin, R. D. 2008. Neuropsychological and behavioral functioning 
in children with and without obstructive sleep apnea referred for tonsillectomy. Journal of the International Neuropsychological Society 14:571-581.

Golan N, Shahar E, Ravid S, Pillar G 2004. Sleep disorders and daytime sleepiness in children with attention-deficit/hyperactive disorder. sleep 27 (2):261-6.

Gonon F 2009. The dopaminergic hypothesis of attention-deficit/hyperactivity disorder needs re-examining. Trends in Neurosciences 32 (1):2-8.

Goraya JS, Cruz M, Valencia I, Kaleyias J, Khurana DS, Hardison HH, Marks H, Legido A, Kothare SV 2009. Sleep Study Abnormalities in Children With Attention Deficit Hyperactivity Disorder. Pediatric Neurology 40 (1):42-46.

Gottlieb, D. J., Chase, C., Vezina, R. M., Heeren, T. C., Corwin, M. J., Auerbach, S. H., WeeseMayer, D. E., Lesko, S. M. 2004. Sleep-disordered breathing symptoms are associated with poorer cognitive function in 5-year-old children. Journal of Pediatrics 145:458-464.

Gozal, D., Wang, M., Pope Jr, D.W. 2001. Objective sleepiness measures in pediatric obstructive sleep apnea. Pediatrics 108 (3):693-697.

Gruber R, Xi T, Frenette S, Rober M, Vannasinh P, Carrier J 2009. Sleep Distrubances in Prepubertal Children with Attention Deficit Hyperactivity Disorder: A Home Polysomnography Study. Sleep 32 (3):343-350.

Guilleminault C, Korobkin R, Winkle R. . 1981. A review of 50 children with obstructive sleep apnea syndrome. . Lung 159:275-287.

Hoban T. 2003. Rhythmic Movement Disorder in Children. CNS Spectrums 8(2): 135-138.

Hodges, E., Felt, B., Giordani, B., Chervin, R. 2011. Sleep Disordered Breathing in Children: A Clinical Guide, Chapter: Behavioral Issues. 2011 (In Press)

Hodges, E.K., Bloomfied, E., Coulas, T., Giordani, B. 2008. Cognitive and behavioral change after adenotonsillectomy in children with sleep-disordered breathing: A review. Minerva Psichiatrica 49 (4):307-320.

Hoebert M, Van Der Heijden KB, Ban Geijlswijk IM, Smits MG 2009. Long-term follow-up of melatonin treatment in children with ADHD and chronic sleep onset insomnia. Journal of Pineal Research 47 (1):1-7.

Iglowstein I, Jenni OG, Molinari L, Largo RH 2003. Sleep Duration From Infancy to Adolescence: Reference Values and Generational Trends. Pediatrics 111 (2):302-307.

Kent JD, Blader JC, Koplewicz HS, Abikoff H, Foley CA 1995. Effects of Late-Afternoon Methylphenidate Administration on Behavior and Sleep in Attention-Deficit Hyperactivity Disorder. Pediatrics 96 (2):320-325.

Khan, AU. 1982. Sleep REM latency in hyperkinetic boys. Am J Psychiatry 139 (10):1358-1360.

Kim HW, Yoon, IY, Cho SC, Kim BN, Chung S, Lee H, Kim CW, Park SK, Yoo HJ 2010. The effect of OROS methylphenidate on the sleep of children with attentiondeficit/hyperactivity disorder. International Clinical Psychopharmacology 25:107-115.

Kirov R, Kinkelbur J, Heipke S, Kostanecka-Endress T, Westoff M, Cohrs S, Ruther E, Hajak G, Banaschewski T, Rothenberger A 2004. Is there a specific polysomnographic sleep pattern in children with attention deficit/hyperactivity disorder? Journal of Sleep Research 13 (1):87-93.

Kollins SH, Jain R, Brams M, Segal S, Findling RL, Wigal SB, Khayrallah M 2011. Clonidine Extended-Release Tablets as Add-on Therapy to Psychostimulants in Children and Adolescents With ADHD. Pediatrics 127 (6):e1406-e1413. 
Konofal, E., Cortese, S., Marchand, M., Arnulf, I., Lecendreux, M. 2007. Impact of restless legs syndrome and iron deficiency on attention-deficit/hyperactivity disorder in children. Sleep Medicine 8:711-715.

Konrad K, Eickhoff SB 2010. Is the ADHD brain wired differently? A review on structural and functional connectivity in attention deficit hyperactivity disorder. Human Brain Mapping 31 (6):904-916.

Kratochvil CJ, Vaughan BS, Stoner JA, Daughton JM, Lubberstedt BD, Murray DW, Chrisman AK, Faircloth MA, Itchon-Ramos NB, Kollins SH, Maayan LA, Greenhill LL, Kotler LA, Fried J, March JS 2011. A Double-Blind, Placebo-Controlled Study of Atomoxetine in Young Children With ADHD. Pediatrics 127 (4):e862-e868.

Lu B, Zee P. 2010. Neurobiology of Sleep. Clinical Chest Medicine 31:309-318.

Makris, N., J. Biederman, M. C. Monuteaux, and L. J. Seidman. 2009. Towards Conceptualizing a Neural Systems-Based Anatomy of Attention-Deficit/Hyperactivity Disorder. Developmental Neuroscience 31 (1-2):36-49.

Mayes, S. D., Calhoun, S. L., Bixler, E. O., Vgontzas, A. N., Mahr, F., Hillwig-Garcia, J., Elamir, B., Edhere-Ekezie, L., Parvin, M. 2009. ADHD Subtypes and Comorbid Anxiety, Depression, and Oppositional-Defiant Disorder: Differences in Sleep Problems. Journal of Pediatric Psychology 34 (3):328-337.

Mick, E., Biederman, J., Jetton, J., Faraone, S. V. . 2000. Sleep Disturbances Associated with Attention Deficit Hyperactivity Disorder: The Impact of Psychiatric Comorbidity and Pharmacotherapy. Journal of Child and Adolescent Psychopharmacology 10 (3):223231.

Mindell JA, Owens JA 2010. A Clinical Guide to Pediatric Sleep: Diagnosis and Management of Sleep Problems. Edited by S. Seigafuse. Second ed. Philadelphia: Lippincott Williams \& Wilkins.

Moore M, Meltzer LJ 2008. The sleepy adolescent: causes and consequences of sleepiness in teens. Paediatric Respiratory Reviews 9 (2):114-121.

Newcorn JH, Kratochvil CJ, Allen AJ, Casat CD, Ruff DD, Moore RJ, Michelson D, and Atomoxetine/Methylphenidate Comparative Study Group. 2008. Atomoxetine and Osmotically Released Methylphenidate for the Treatment of Attention Deficit Hyperactivity Disorder: Acute Comparison and Differential Response. Am J Psychiatry 165 (6):721-730.

Nigg, J. T. 2005. Neuropsychologic Theory and Findings in Attention-Deficit/ Hyperactivity Disorder: The State of the Field and Salient Challenges for the Coming Decade. Society of Biological Psychiatry 57:1424-1435.

O'Brien, L. M., Gozal, D. 2004. Neurocognitive dysfunction and sleep in children: from human to rodent. The Pediatric Clinics of North America 51:187-202.

O'Brien, L. M., Holbrook, C. R., Mervis, C. B., Klaus, C. J., Bruner, J. L., Raffield, T. J., Rutherford, J., Mehl, R. C., Wang, M., Tuell, A., Hume, B. C., Gozal, D. 2003. Sleep and Neurobehavioral Characteristics of 5- to 7-Year-Old Children With Parentally Reported Symptoms of

Attention-Deficit/Hyperactivity Disorder. Pediatrics 111 (3):554-563. O'Brien, L. M., Icanenko, A., Crabtree, V. M., Holbrook, C. R., Bruner, J. L., Klaus, C. J., Gozal, D. . 2003. Sleep Disturbances in Children with Attention Deficit Hyperactivity Disorder. Pediatric Research 54 (2):237-243. 
O’Brien, L. M., Tauman, R., Gozal, D. 2004. Sleep Pressure Correlates of Cognitive and Behavioral Morbidity in Snoring Children. Sleep 27 (2):279-282.

Oner, P., Dirik, E.B., Taner, Y., et al. 2007. Association between low serum ferritin and restless legs syndrome in patients with attention deficit hyperactivity disorder. Tohoku J Exp Med 213:269-276.

Owens, J. A., and V. Dalzell. 2005. Use of the 'BEARS' sleep screening tool in a pediatric residents' continuity clinic: a pilot study. Sleep Med 6 (1):63-9.

Owens, J. A., Maxim, R., Nobile, C., McGuinn, M., Msall, M. 2000. Parental and Self-report of Sleep in Children With Attention-Deficit/Hyperactivity Disorder. Arch Pediatr Adolesc Med. 154:549-555.

Owens, J. A., Spirito, A., McGuinn, M., Nobile, C. . 2000. Sleep Habits and Sleep Distrubance in Elementary School-Aged Children Developmental and Behavioral Pediatrics 21 (1):27-37.

Owens, J.A. 2005. The ADHD and Sleep Conundrum: A Review. Developmental and Behavioral Pediatrics 6 (4):312-322.

Owens, J.A. 2008. Classification and Epidemiology of Childhood Sleep Disorders. Primary Care: Clinics in Office Practice 35:533-546.

Pace-Schott E.F., Edward F., and Hobson A. 2002. The Neurobiology of Sleep: Genetics, cellular physiology and subcortical networks. Nat Rev Neurosci 3 (8):591-605.

Picchietti, D. L., England, S. J., Walters, A. S., Willis, K., Verrico, T. . 1998. Periodic Limb Movement Disorder and Restless Legs Syndrome in Children With Attentiondeficit Hyperactivity Disorder. Journal of Child Neurology 13:588-594.

Picchietti, M. A., Picchietti, D. L. 2008. Restless Legs Syndrome and Periodic Limb Movement Disorder in Children and Adolescents. Seminars in Pediatric Neurology 15:91-99.

Pichietti, D.L., et al. 2007. Restless legs syndrome: prevalence and impact in children and adolescents - the Peds REST study. Pediatrics 120:253-266.

Plizka S and AACAP Work Group on Quality Issues. 2007. Practice Parameter for the Assessment and Treatment of Children and Adolescents with AttentionDeficit/Hyperactivity Disorder. Journal of American Academy of Child and Adolescent Psychiatry 46 (7):894-921.

Rajaram, S., Walters, A.S., England, S.J., Mehta, D., Nizam, F. 2004. Some children with growing pains may actually have restless legs syndrome. Sleep 27:767-773.

Reid, G.J., Hong, R.Y., Wade, T.J. 2009. The relation between common sleep problems and emotional and behavioral problems among 2- and 3-year-olds in the context of known risk factors for psychopathology. Journal of Sleep Research 18:49-59.

Rosa-Neto P, Lou HC, Cumming P, Pryds O, Karrebaek H, Lunding J, Gjedde A. 2005. Methylphenidate-evoked changes in striatal dopamine correlate with inattention and impulsivity in adolescents with attention deficit hyperactivity disorder. NeuroImage 25 (3):868-876.

Rubia, K., R. Halari, A. M. Mohammad, E. Taylor, and M. Brammer. 2011. Methylphenidate normalizes frontocingulate underactivation during error processing in attentiondeficit/hyperactivity disorder. Biol Psychiatry 70 (3):255-62.

Sadeh, A., Gruber, R., Raviv, A. 2002. Sleep, Neurobehavioral Functioning, and Behavior Problems in School-Age Children. Child Development 73 (2):405-417. 
Sangal. R.B., Sangal, J.M. 2004. Rating scales for inattention and sleepiness are correlated in adults with symptoms of sleep disordered breathing syndrome, but not in adults with symptoms of attention-deficit/hyperactivity disorder. Sleep Medicine 5:133135.

Shur-Fen G, S. 2006. Prevalence of sleep problems and their association with inattention/hyperactivity among children aged 6-15 in Taiwan. Journal of Sleep Research 15:403-414.

Silvestri R, Gagliano A, Arico I, Calarese T, Cedro C, Bruni O, Condurso R, Germano E, Gervasi G, Siracusano R, Vita G, Bramani P 2009. Sleep disorders in children with Attention-Deficit/Hyperactivity Disorder (ADHD) recorded overnight by videopolysomnography. Sleep Medicine 10 (10):1132-1138.

Simonds, J.F., Parraga, H. 1984. Sleep Behaviors and Disorders in Children and Adolescents Evaluated at Psychiatric Clinics. Developmental and Behavioral Pediatrics 5 (1):6-10.

Stein, M.A., Mendelsohn, J., Obermeyer, W.H., Amromin, J., Benca, R. 2001. Sleep and Behavior Problems in School-Aged Children. Pediatrics 107 (4).

Swanson, J.M., Flodman, P., Kennedy, J., Spence, M.A., Moyzis, R., Schucka, S., Murias, M., Moriarity, J., Barr, C., Smith, M., Posner, M. 2000. Dopamine genes and ADHD. Neuroscience and Biobehavioral Reviews 25:21-25.

Tripp, G., Wickens, J.R. 2009. Neurobiology of ADHD. Neuropharmacology 57:579-589.

Van Der Heijden KB, Smits MG, Gunning WB. 2006. Sleep hygiene and actigraphically evaluated sleep characteristics in children with ADHD and chronic sleep onset insomnia. Journal of Sleep Research 15 (1):55-62.

Walters, A.S., Pichietti, D.L., Ehrenberg, B.L., Wagner, M.L. 1994. Restless legs syndrome in childhood and adolescence. Pediatric Neurology 11:241-245.

Walters, A.S., Silvestri, R., Zucconi, M., Chandrashedariah, R., Konofal, E. 2008. Review of the possibile relationship and hypothetical links between attention deficit hyperactivity disorder (ADHD) and the simple sleep related movement disorders, parasomnias, hypersomnias, and circadian rhythm disorders. Journal of Clinical Sleep Medicine 4:591-600.

Zimmer L 2009. Positron emission tomography neuroimaging for a better understanding of the biology of ADHD. Neuropharmacology 57 (7-8):601-607. 


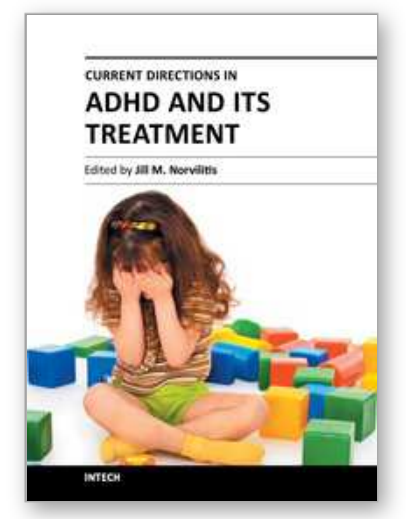

\author{
Current Directions in ADHD and Its Treatment \\ Edited by Dr. Jill M. Norvilitis
}

ISBN 978-953-307-868-7

Hard cover, 302 pages

Publisher InTech

Published online 15, February, 2012

Published in print edition February, 2012

The treatment of Attention Deficit Hyperactivity Disorder is a matter of ongoing research and debate, with considerable data supporting both psychopharmacological and behavioral approaches. Researchers continue to search for new interventions to be used in conjunction with or in place of the more traditional approaches. These interventions run the gamut from social skills training to cognitive behavioral interventions to meditation to neuropsychologically-based techniques. The goal of this volume is to explore the state-of-the-art in considerations in the treatment of ADHD around the world. This broad survey covers issues related to comorbidity that affect the treatment choices that are made, the effects of psychopharmacology, and nonmedication treatments, with a special section devoted to the controversial new treatment, neurofeedback. There is something in this volume for everyone interested in the treatment of ADHD, from students examining the topic for the first time to researchers and practitioners looking for inspiration for new research questions or potential interventions.

\title{
How to reference
}

In order to correctly reference this scholarly work, feel free to copy and paste the following:

Elizabeth Hastings and Barbara T. Felt (2012). ADHD and Sleep Problems in Children, Current Directions in ADHD and Its Treatment, Dr. Jill M. Norvilitis (Ed.), ISBN: 978-953-307-868-7, InTech, Available from: http://www.intechopen.com/books/current-directions-in-adhd-and-its-treatment/adhd-and-sleep-problems-inchildren

\section{INTECH}

open science | open minds

\section{InTech Europe}

University Campus STeP Ri

Slavka Krautzeka 83/A

51000 Rijeka, Croatia

Phone: +385 (51) 770447

Fax: +385 (51) 686166

www.intechopen.com

\section{InTech China}

Unit 405, Office Block, Hotel Equatorial Shanghai

No.65, Yan An Road (West), Shanghai, 200040, China

中国上海市延安西路65号上海国际贵都大饭店办公楼 405 单元

Phone: +86-21-62489820

Fax: $+86-21-62489821$ 
(C) 2012 The Author(s). Licensee IntechOpen. This is an open access article distributed under the terms of the Creative Commons Attribution 3.0 License, which permits unrestricted use, distribution, and reproduction in any medium, provided the original work is properly cited. 